\title{
Innovating in Circles
}

\section{A Qualitative Analysis on Cycles of IT Feature Recombinations for Per- formative and Creative Outcomes}

\author{
Katharina Ebner ${ }^{1}$, Geneviève Bassellier ${ }^{2}$, and Stefan Smolnik ${ }^{1}$ \\ ${ }^{1}$ University of Hagen, Germany \\ 2 McGill University, Montreal, Canada
}

\begin{abstract}
Innovations do not emerge in isolation but are at least to some extent recombinations of previously existing building blocks. In this paper, we will build on the recombination processes feature set broadening and deepening to show how individuals innovate with IT. In our understanding, the out-comes of innovative use can be performative (improving existing task performance) or creative (leading to new deliverables). We build on a longitudinal case of stresstracking initially designed to improve meditation, but ultimately increasing work productivity by using the meditation tool in an innovative way. Using a theoretically grounded analysis framework, we were able to derive eight propositions on the attainment of performative and creative outcome of innovative IT use. We postulate that innovation only occurs through repeating cycles of recombination processes. Particularly, we propose that it is instrumental to run through a phase that does not benefit any task-related outcomes to trigger true creative outcomes.
\end{abstract}

Keywords: IT post-adoption, IT innovation, IT features, recombination, learning cycles

\section{Introduction}

The attainment of innovations is a complex, non-linear process [1]. There is a common understanding among scholars that innovations do not emerge in isolation but are at least to some extent resulting from the recombinations of previously existing building blocks [2], [3], [4]. By recombination, we refer to a process that brings existing knowledge, known system features, etc. together in a novel way thus allowing new application scenarios and new knowledge to emerge [4]. Innovation by recombination manifests in two fundamental processes - the acquisition of new knowledge and the transformation of existing knowledge which have in an information technology (IT) context been conceptualized as scanning and evaluating [5], knowledge acquisition and conversion [6], sensing and experimentation [7], or, when referring to specific features, building blocks or knowledge assets, as deepening and broadening [2], [7], [8]. In this paper, we will build on these two recombination processes, feature set broadening and feature set deepening, to show how individuals innovate with IT. We employ a broad conceptualization of innovative IT use in that we define it as covering all types of IT use aimed at finding new uses on an existing IT. These new uses involve users that optimize task-performance of existing tasks [9], [10] as well as uses that result in novel deliverables, e.g. new processes, new products, [11], [12], [13]. As a result, the outcomes of innovative use can be performative (i.e. improving existing task performance) or creative (i.e. leading to new deliverables, may it be tasks, processes, or products) with performative outcomes being visible rather in the short-term, and creative outcomes in the longer term. Looking at the long-term outcomes of IT use, such as individual innovativeness, has also been the recent subject of call for future research [14]. Following this call for research, we seek to an- 
swer the research question: Which patterns of recombination processes occur during individuals' innovating with IT, and how these processes impact different outcomes of innovative IT use?

To address our research objectives, besides recombination research, we build on and extend research on adopting and innovating with IT. We see our work rooted in research on IT use as feature adaptation, [8], [15] [16], [17], [18]. We thus build on the concept of deep structure IT usage introduced by [19] and define IT use as "an individual user's employment of one or more features of a system to perform a task" (p. 231), where a task "is a goaldirected activity performed by a user" (p. 231). In the same vein, we will investigate innovative IT use with a lens on the features of IT and link them to IT-enabled outcomes, i.e. IT use is comprised of a system (represented by its features), a user (represented by the learning associated with feature set broadening and deepening) and a task (addressed by feature set). Given this theoretical embedding, our research is rooted in the post-adoptive stage of IT use where users already adopted a new technology and have been using it for some time. We employ a longitudinal qualitative research setting using a rich case of a self-tracker, who constantly changed his use of a stress tracking device from simple meditation to, eventually, a creative use configuration allowing him to sense stress at work, address prejudicial workrelated behavioral patterns, and increase his work-related performance.

\section{Theoretical background and development}

\section{Performative IT use outcomes}

Papers investigating the performative aspect of individual innovativeness focus on optimizing work performance, i.e., increasing efficiency and effectiveness in completing existing tasks with the objective to improve organizational performance [6], [9], [10], [20]. Following [21] and [22], efficiency is the level of goal attainment for a given level of input and effectiveness is the degree to which the task goals are met. Accordingly, we use the following definitions for efficiency and effectiveness in this paper: Efficiency is the level of goal-attainment of a task a user performs with an IT for a given level of input (e.g. time, effort). Effectiveness is the degree to which the goals of a task a user performs with an IT are met.

Hence, an improvement in efficiency relates to performing a task by using less features or using the features with less effort or time or thinking while keeping the task output at the same level. By contrast, effectiveness improves the task output by making it more complete or more correct (e.g. through using different features). IT use associated with an improvement of effectiveness requires a deeper understanding of an IT's features and a higher level of experience. Effectiveness is, therefore, often conceptualized to be preceded by efficiency and related use types [23], [24].

\section{Creative IT use outcomes}

Papers investigating the creative aspect of individual innovativeness focus on the emergence of new deliverables by using an existing IT. These new deliverables may involve new tasks, goals, or practices [11], [15], [6]. On a higher level, such new deliverables may not just impact how an IT is used as tool, they may also impact associated roles, processes, and procedures involving an IT's use [23]. Hence, individual innovativeness may have an impact on task performance and eventually lead to "true" innovation in that an organization has gained insights on e.g. how to offer new services to customers [2], [25]. From an individual perspective, it is important to clarify the conditions under which the use of IT can be considered as "novel" [13]. Management scholars frequently measure innovativeness by considering how novel an innovation is to a specific team or individual [25], [26], and purposefully abstract from a larger network perspective. Indeed, even though the use of an IT in a specific way is innovative for a given individual, from a broader perspective, it may be that the individual is only closing up to the knowledge level of colleagues. At the individual level, it remains an innovative use. Following this argumentation, we define the creative outcomes of individual 
innovativeness as follows: Creative outcomes of innovativeness refer to new tasks that can be solved using an IT and that were previously unknown to an individual.

\section{Feature set broadening and deepening}

System features are the functional building blocks of an information system [18], [27]. They reflect the "specific types of rules and resources, or capabilities, offered by the system" [28] and result from both the design process and individual decisions about use [27]. System features may be grouped, or (re-)combined in feature set [8], [18], [27]. Building on the literature above, we define a feature set as a group of features that an individual has associated together and assigned to one task or a group of tasks (see Figures 1 and 2). Accordingly, feature sets are the result of individual cognition processes and may involve all features available in an information system or only parts of them. The configuration of these feature sets depends on available knowledge and cognitive absorption [19], [28] and is, thus, constantly changing and adjusted by the user. Feature sets have been used by various authors who build on the system-user-task structure introduced by [19]. For instance, [8] investigates how a change in the configuration of a user's mental feature subsets related to specific task groups may lead to distal and mid-term task-performance outcomes. Furthermore, [15] describe how reconfigurations of task-related feature set may help gaining higher levels of innovativeness. The idea to employ feature set reconfigurations to explain creative outcomes of IT use can also be found at [6]. Researchers have also investigated how the feature sets of a user change as she either extend her use behavior, or reduces and resists using features of an IT [10], [15], [27]. For example, [18] describes "a user's revisions of which and how system features are used" (p. 453). He distinguishes between four behaviors (trying new features, feature substituting, feature combining, and feature repurposing). Similarly, [15] reflect novel ways of employing IT features that involve either using a formerly unused set of available features, using IT features for additional tasks, or using feature extensions. [10] and [17] have also discussed the concept of feature extensions. In sum, prior research shows that the changes to a user's feature sets operate through the recombination processes feature set broadening and deepening.

As users broaden their feature set, they acquire knowledge on new features and, hence, extend the scope and variety of IT features they can apply for task completion [27]. However, simply using more features alone is not sufficient, since they may be used in an unproductive way [8]. Feature set broadening is the process of "actively extending the basket of IT features that may be used by a particular user to accomplish tasks" [8]. We have summarized conceptualizations of feature set broadening in Table 1. All of the conceptualizations build on the role of features and their relationships with existing and new tasks. The broadening process, hence, tightly links to the learning of new features.

Table 1. Conceptualizations of feature set broadening.

\begin{tabular}{|l|l|}
\hline$[27]$ & $\begin{array}{l}\text { IT sensemaking, during which users consciously include or exclude features } \\
\text { into their task solving. }\end{array}$ \\
\hline$[8]$ & $\begin{array}{l}\text { Obtaining a broad grasp of a system's functionality while actively extending } \\
\text { the basket of IT features that may be used to accomplish tasks. }\end{array}$ \\
\hline$[10],[16]$ & Learning and using more of the functions available in the IT. \\
\hline$[18]$ & $\begin{array}{l}\text { Extension/adjustment of the content of the features in use to cope with chang- } \\
\text { ing environment. }\end{array}$ \\
\hline$[29]$ & $\begin{array}{l}\text { Learn how to use entirely new IT features. } \\
\text { Extent to which an individual uses the various features of the IS system in } \\
\text { question. }\end{array}$ \\
\hline$[30]$ &
\end{tabular}

Two different manifestations of feature set broadening exist [15], [17], [18], with each having a different task-related impact (Figure 1). The knowledge acquisition may lead to an extension of the task-related feature set, or to an extension of the features in use without any task association. Accordingly, in the first case the user has more task-solving options and may thus come up with better, situation-tailored solutions due to higher flexibility. In the case of an 
extension of the features in use without any task association, the user better grasps the IT's features and capabilities, and may thus come up with new application scenarios of the IT.

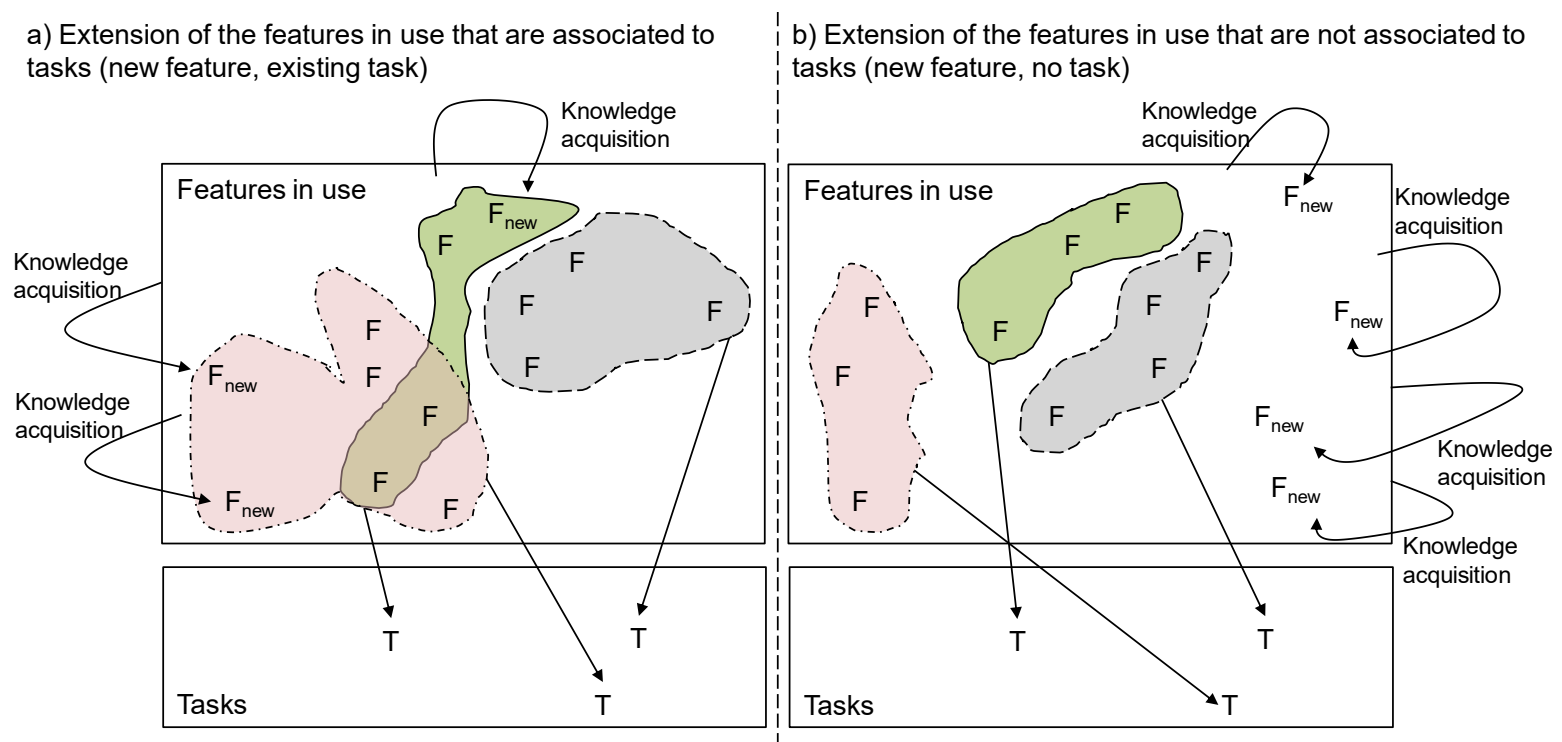

Figure 1. Configurations of feature set broadening.

Feature set deepening involves the transformation of task-solving-related knowledge (i.e. the creation and modification of "how-to knowledge") and requires the user to connect different features to current and potential tasks [6]. The higher the feature set depth, the better will be the solutions produced to solve tasks. We have summarized different conceptualizations of feature set deepening in Table 2. The table shows that the deepening process is often linked to individual abilities in mastering an IT. Hence, it involves a transformation of existing and new feature set by recombining, substituting, or removing included features. Technically, an increase in feature set depth has also been linked to the number of feature combinations [18], [28], the number and length of sequences of features [29], or the number of feature set (i.e. the number of tasks that can be solved) [8], [28].

Table 2. Conceptualizations of feature set deepening.

\begin{tabular}{|l|l|}
\hline$[28]$ & Different combinations of features to find a solution for solving a task. \\
\hline$[10]$ & $\begin{array}{l}\text { Understanding of how to use IT features and how these features complement other } \\
\text { features. }\end{array}$ \\
\hline$[18]$ & $\begin{array}{l}\text { Feature combining or repurposing as an adaptation of how the features are used, } \\
\text { separately or together, in an existing or new way. }\end{array}$ \\
\hline$[29]$ & Learn how to apply known IT features in entirely new sequences and contexts. \\
\hline$[8]$ & $\begin{array}{l}\text { Increase the mastery of already known features and functionalities. Fully grasp the } \\
\text { features' affordances, effects, and their associations with already-known IT features. }\end{array}$ \\
\hline$[19]$ & $\begin{array}{l}\text { Extent to which features in the system that relate to the core aspects of the task are } \\
\text { used. }\end{array}$ \\
\hline
\end{tabular}

Two manifestations of feature set deepening exist (Figure 2). The deepening may lead to a modification of existing task-related feature sets. In this regard, feature sets may be recombined or adjusted by repurposing, adding or removing features [18], [31]. The know-ledge transformation may also lead to a compilation of new feature sets for new tasks [8], [32]. In sum, a theoretical postulate in this paper is that the only way to include new features into feature set is by feature set broadening, and the only process by which new tasks can be addressed is by feature set deepening. Using this understanding as research framework, we will next show how feature set broadening and deepening lead to innovative outcomes in a real-world IT adoption case. 

\begin{tabular}{l|l}
$\begin{array}{l}\text { a) Modification of feature sets by re-adjusting and removing } \\
\text { included features (existing feature, existing task) }\end{array}$ & bompilation of new feature sets for new tasks (existing \\
$\begin{array}{ll}\text { feature, new task) }\end{array}$
\end{tabular}
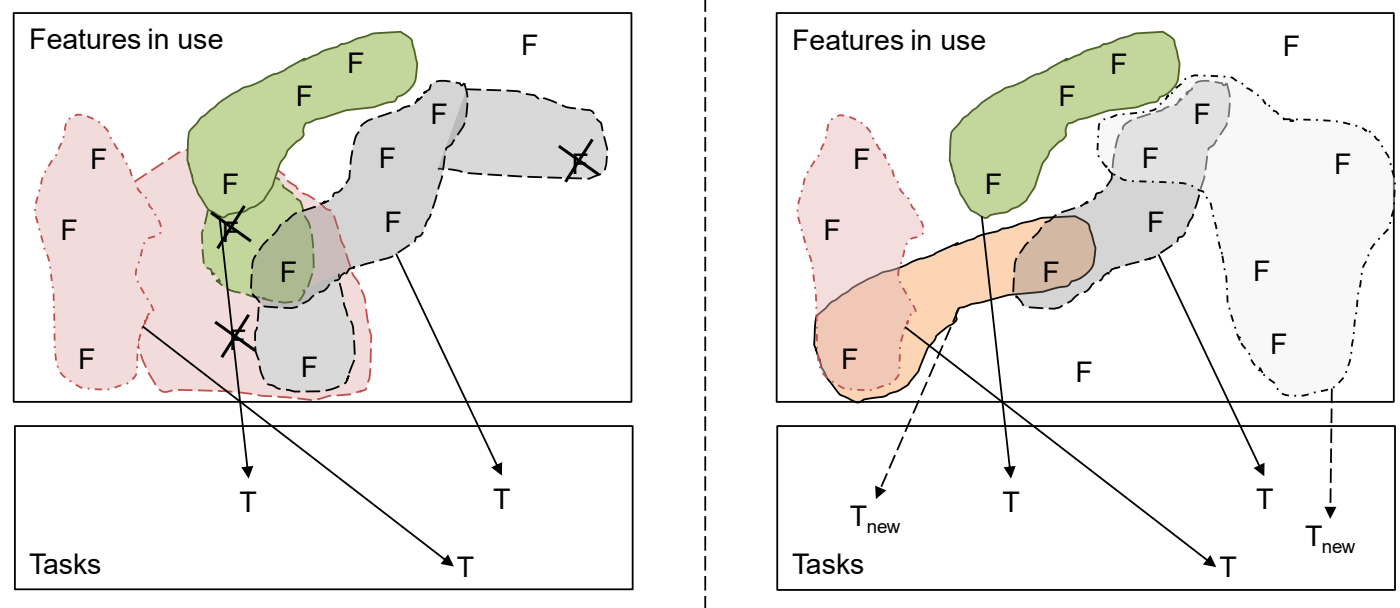

Figure 2. Configurations of feature set deepening.

\section{Research method}

We decided for a qualitative research setup [33], [34], [35] to capture the multifaceted phenomena related to innovative IT use. We chose a case of an innovative self-tracker, John, to which we had access via the professional network of one of the co-authors and who, in a private effort to improve his meditation, found a way to become more productive at work using the same IS that he used for meditation. Table 3 presents a brief profile of the case.

Table 3. Case profile.

\begin{tabular}{|l|l|}
\hline Context & Stress tracking to increase work productivity \\
\hline Origin & $\begin{array}{l}\text { John works as a professional data analyst and, as a hobby, organizes a } \\
\text { large group of self-trackers from the USA }\end{array}$ \\
\hline IT & emWave2, a tool for tracking and visualizing heart rate variability \\
\hline $\begin{array}{l}\text { \# of feature set } \\
\text { recombinations }\end{array}$ & $\begin{array}{l}\text { Feature set broadening: } 4 \\
\text { Feature set deepening: } 3\end{array}$ \\
\hline Affected tasks & Stress reduction, investigating the occurrences of stress \\
\hline Impacted outcomes & Performative and creative outcomes of innovative IT use \\
\hline
\end{tabular}

We employed multiple data sources for our analysis. We reverted to three different detailed presentations on John's stress tracking he gave on his experiences between 2012 and 2015. Contrasting John's different presentations as part of the data analysis allowed us not only to construct his course of adoption longitudinally. We were also able to triangulate our findings by analyzing John's varying emphasis of certain aspects of his adoption over time. This way, we could differentiate routine use from innovation processes, construct a logical chain of evidence, and rule out rival explanations [35], [36]. To further enrich and triangulate our database, we systematically browsed and analyzed John's tweets between January 2011 (beginning of stress tracking) and May 2016. We further analyzed two interviews he gave to selftracking magazines, browsed and collected relevant posts from all his forum activities in the self-tracking forum of his group. We also compiled a case diary and detailed case write-up.

For our data analysis, we first developed a detailed code list, in which we operationalized our major concepts using established definitions and operationalizations [8], [18], [19], [27]. We came up with altogether twenty codes representing the different feature set recombinations, the deep structure usage, outcomes, features, and tasks. One of the co-authors selectively coded the collected empirical materials [35] using the qualitative data analysis software Atlas.ti (version 8). Another co-author performed a detailed review and revision of the coding. Different interpretations were discussed by these two co-authors and resolved by rechecking the different data sources to increase coding reliability and reduce coding bias. Ad- 
ditionally, one further co-author was asked to provide input regarding the coding of randomly chosen excerpts or those whose interpretation was difficult, thus, helping to exclude rival explanations [34]. The pattern coding was performed jointly by the same two co-authors [35]. The goal of this step was to detect re- and co-occurring patterns of feature set modifications and their relationship to performative and creative outcomes during the IT use process. To that end, the initial codes were grouped together into synthesizing categories [33]. High-level code categories and the relationships between them were organized with help of network displays [35], which also fostered the building of logical chains of evidence.

\section{Case description}

Having started with tracking his sleep in 2005 , John has gone on to engage with tracking stress. He tracks his stress levels using emWave2, a tool for tracking and visualizing heart rate variability (HRV). John has experimented with hooking up his HRV tool to his computer while working and installed software to alert him when it detects periods of stress. John understood how particular behaviors acted as triggers and how he could manage those triggers in order to reduce and defuse stress, and ultimately, through a number of learning cycles, increase his work productivity by using the HRV tool in an innovative way. John bought his HRV tool initially for meditation to relax. The way the HRV tool is intended to be used is to sit down every day twice for at least 10 minutes each time and meditate by putting a thumb on a sensor that senses the heartbeat. If the heartbeat is mild and regular, the tool will play a sound and show a green light. If the heartbeat is moderately regular, the sound will be different and a blue light is shown. If the heartbeat is hectically, thus indicating restlessness and stress, no sound is played and a red light is shown. Beyond using a thumb on the sensor, the user can also employ an ear clip to track the heartbeat. The tool also shows an oscillating light moving in the speed of the heartbeat. There is an app available that can support meditation by visualizing the heart rate, logging and scheduling the meditation times, configuring the sensitivity of three meditation stages (red, blue, green) and configuring the sounds.

John started using the tool with the thumb sensor and by listening to the sounds, trying to adjust his breathing this way. After a while, he noticed the ear clip device as reported during his first presentation in 2012: "And so I found out there is this ear clip accessory and so you put that on attached to the device and you use it with hands free." Meditating this way allowed him to improve his meditation by putting the HRV tool on a chair and focus on the oscillating light of the tool: "So, in a way it was actually kind of cheating the meditation, I was trying to abandon stalls by looking at the device and trying to stay in green - but I felt a lot better afterwards [he laughs]." Reflecting on his initial use, John subsumed "So, I tried doing that [way of meditation], but it didn't work for me. The reason why is that during [meditation], I feel okay, but then I would get stressed later in the day... And I also found out that any kind of habit that requires me to carve out time, even if it's just 10 minutes, would be very hard to adopt for me." Despite these downsides, John kept meditating irregularly using the tool: "Using emWave, I became a lot better at meditating. [...] So, actually spending some time with the device helped me - it just ain't doing it [the stress reducing] quick enough for me to really appreciate it." Realizing that the meditation would only moderately help with his stress problem, John started exploring the app available for the tool. He was interested in the "challenge levels" - an app feature that could be used to configure the sensitivity of the tool to determine a green, blue, or red state. By setting the challenge level to hard (i.e. for a green state an extremely constant heartrate was required) he tried to become more balanced and hoped the state would last longer. But he struggled to reach the green state then and reset it to the previous setting. He kept exploring the app and came across a feature to configure the sounds, for which he had immediately no idea about which task he could meaningfully use it for: not only the sound itself could be changed, it was also possible to activate or deactivate the red, blue, or green sounds. John remembered: "And then [after a while] I was thinking: well if the whole point of this is to be in green as much as possible and to reduce the amount of time that you are actually in red during the day, I need some sort of alert system, some sort of waver to tell me when I'm feeling stressed and through some creative configuration, I was 
actually able to setup such a system using emWave." This "creative configuration" involved using the tool with the ear clip all day during work and tracking his HRV as indicator of stress constantly: "I turned off the tones for the green and the blue and just left on the red one. So, that's how it alerted me when I was in stress and the protocol that whenever I would here that tone, I would stop what I was doing, turn to it, and do, yeah, deep breathing until I got into a blue state or into that green state and then I go back to work."

Tracking his stress during the day eventually helped John recognizing some productivity affecting negative behaviors: "I started detecting behavioral patterns I wasn't aware of before. So, I checked the news a lot during the day I work. And I noticed that whenever I opened up Google News, the alert would go off. Well, it wasn't the news that was stressing me out. What it was: the stress was actually a trigger and checking the news was the behavior to kind of get away from the stress [...]. As you can imagine that cycle would repeat many times throughout the day." As a result, John installed a website blocker to block such stress reduction sites, and instead took a deep breathe. This was not just less time-consuming, it also helped reducing the stress feeling more effectively than checking news websites: "I am not going to make some statement like 'I am not feeling stressed anymore.' I still do. I mean, there are still some patterns ..., but I am making progress. And I think it's because now I can better understand where the problem is and have a good way of marking that progress."

\section{Results}

Our data analysis reveals three findings. First, successful feature set broadening and deepening alternate constantly in cycles. Second, a cycle is always initiated by a broadening. Third, different configurations of feature set broadening and deepening impact different outcomes, and to come up with creative outcomes, it is instrumental to pass through a broadening that does not immediately relate to a task. We summarized the broadening and deepening phases in Table 4 and illustrate the development of stress reduction in Figure 3.

Table 4. Summary of case analysis: cycles of broadening and deepening.

\begin{tabular}{|c|c|c|}
\hline $\begin{array}{l}\text { Feature set } \\
\text { modification }\end{array}$ & Description & Impacted outcomes \\
\hline $\begin{array}{l}\# 0 \\
\text { Original use }\end{array}$ & $\begin{array}{l}\text { Meditate using the thumb sensor, with closed } \\
\text { eyes, sitting on the floor, infrequently check } \\
\text { oscillating light to see heartrate } \\
\text { Features included in feature set: thumb sensor, } \\
\text { sounds, lights }\end{array}$ & $\begin{array}{l}\text { Meditation and stress reduction } \\
\text { considered inefficient and ineffec- } \\
\text { tive. }\end{array}$ \\
\hline $\begin{array}{l}\text { \#1 } \\
\text { Feature set } \\
\text { broadening } \\
\text { (new feature, } \\
\text { existing task) }\end{array}$ & $\begin{array}{l}\text { Include ear clip into used features for medita- } \\
\text { tion } \\
\text { Features included in feature set: ear clip, thumb } \\
\text { sensor, sounds, lights } \\
\text { Task: stress reduction }\end{array}$ & $\begin{array}{l}\text { Having hands free and having not } \\
\text { to constantly push thumb on sensor } \\
\text { led to higher level of meditation, } \\
\text { thus increasing the effectiveness of } \\
\text { meditation. }\end{array}$ \\
\hline $\begin{array}{l}\# 2 \\
\text { Feature set } \\
\text { deepening } \\
\text { (existing fea- } \\
\text { ture, existing } \\
\text { task) }\end{array}$ & $\begin{array}{l}\text { Replace thumb sensor constantly by ear clip, } \\
\text { place HRV tool on chair, focus on oscillating } \\
\text { light } \\
\text { Features included in feature set: ear clip, } \\
\text { sounds, lights } \\
\text { Task: stress reduction }\end{array}$ & $\begin{array}{l}\text { Focus on oscillating light got John } \\
\text { quicker into green state, thus in- } \\
\text { creasing efficiency of meditation. } \\
\text { He was also able to stay a lot long- } \\
\text { er in green state, thus indicating } \\
\text { increased effectiveness. }\end{array}$ \\
\hline $\begin{array}{l}\text { \#3 } \\
\text { Feature set } \\
\text { broadening } \\
\text { (new feature, } \\
\text { existing task) }\end{array}$ & $\begin{array}{l}\text { Explore app offered for the tool to learn chal- } \\
\text { lenge levels } \\
\text { Features included in feature set: ear clip, } \\
\text { sounds, lights, app/challenge levels } \\
\text { Task: stress reduction }\end{array}$ & $\begin{array}{l}\text { Unsuccessful, no impact on out- } \\
\text { comes - challenge levels were too } \\
\text { difficult. Reset to previous feature } \\
\text { set configuration. }\end{array}$ \\
\hline $\begin{array}{l}\text { \#4 } \\
\text { Feature set } \\
\text { broadening } \\
\text { (new feature, } \\
\text { no task) }\end{array}$ & $\begin{array}{l}\text { Discover sound configuration option in tool } \\
\text { Features included in feature set: ear clip, } \\
\text { sounds, lights, app/sound configuration } \\
\text { Task: no task at that point }\end{array}$ & $\begin{array}{l}\text { The discovering of the sound con- } \\
\text { figuration left John wondering what } \\
\text { it would be good for, but no imme- } \\
\text { diate impact happened. }\end{array}$ \\
\hline
\end{tabular}




\begin{tabular}{|c|c|c|}
\hline $\begin{array}{l}\text { \#5 } \\
\text { Feature set } \\
\text { deepening } \\
\text { (existing fea- } \\
\text { ture, new } \\
\text { task) }\end{array}$ & $\begin{array}{l}\text { Understand that the sound configuration could } \\
\text { be used to configure a stress alert system } \\
\text { Features included in new feature set: ear clip, } \\
\text { sounds, app/sound configuration } \\
\text { Task: investigating the occurrences of stress }\end{array}$ & $\begin{array}{l}\text { No impact on efficiency and effec- } \\
\text { tiveness of meditation or work, but } \\
\text { creative outcome. }\end{array}$ \\
\hline $\begin{array}{l}\text { \#6 } \\
\text { Feature set } \\
\text { broadening } \\
\text { (new feature, } \\
\text { existing task) }\end{array}$ & $\begin{array}{l}\text { Install a website blocker } \\
\text { Features included in feature set: ear clip, } \\
\text { sounds, app/sound configuration, website } \\
\text { blocker } \\
\text { Task: stress reduction }\end{array}$ & $\begin{array}{l}\text { Since the website blocker prevent- } \\
\text { ed prejudicial behavior, he was able } \\
\text { to stay more focused on tasks, thus } \\
\text { increasing effectiveness of reducing } \\
\text { stress. }\end{array}$ \\
\hline $\begin{array}{l}\# 7 \\
\text { Feature set } \\
\text { deepening } \\
\text { (existing fea- } \\
\text { ture, existing } \\
\text { task) }\end{array}$ & $\begin{array}{l}\text { Do not just block websites. To better overcome } \\
\text { stress overreaction, perform conscious breath- } \\
\text { ing during work (around 1-3 minutes) } \\
\text { Features included in feature set: ear clip, } \\
\text { sounds, app/sound configuration, website } \\
\text { blocker } \\
\text { Task: stress reduction }\end{array}$ & $\begin{array}{l}\text { The breathing helped in reducing } \\
\text { stress states quicker, thus reducing } \\
\text { stress levels more efficiently, and - } \\
\text { since he actively and sustainably } \\
\text { reduces his stress level - also was } \\
\text { more effectively in reducing stress. }\end{array}$ \\
\hline
\end{tabular}

As can be seen from Figure 3, with four out of seven feature set modifications John was able to improve his stress level. In essence, the stress level at the end of iteration 7 was much less during and the end of the day than in iteration 0 . However, only after iteration 5 , when John started realizing his actual stress curve, he was able in his future feature set modifications to improve the effectiveness and efficiency of stress reduction. The relative development of the change in stress reduction effectiveness and efficiency is displayed in Figure 4. As can be seen from this figure, there is a more frequent increase in effectiveness than in efficiency. There were also periods of stagnation, which was terminated by a "no task - new task" pattern. Furthermore, there is the same increase pattern in effectiveness and efficiency at the beginning and the end of the observed feature set modifications. Reflecting these observations jointly with the summary presented in Table 4 indicates that successful feature set recombinations always alternate. The only exception from this reoccurring pattern was \#3, which was reset due to unsuccessful recombination. Furthermore, the starting point to a new cycle is always the broadening. We derive:

\section{P1a: Feature set recombination will always alternate between feature set broadening and deepening.}

\section{P1b: A feature set recombination cycle will always start with a broadening.}

P1c: Unsuccessful recombination processes are reset, and a new cycle begins regardless of the last recombination process.

Backing for our propositions comes from recent literature on IT use. For instance, [37] show that all forms of IT use are the result of two different types of cognition processes that interact in cyclical patterns but leave the details of associated use or outcomes open for future research. Several studies have documented a nonlinear relationship between experience and creativity or innovation: increased experience contributes to creativity and innovation up to a certain point, with diminishing returns at high levels of experience [38], [39], [40]. For instance, [3] indicate that this complex relationship might result from the actual context of routines and practices in which creativity occurs, since some routines seem more or less favorable to creativity or innovation. However, the actual relationship between these concepts and innovativeness remains mostly unexplored. As a result, the generation of creative outcomes of innovativeness has consistently been pointed out as the more complex, more uncertain and hazardously type of innovativeness, but also the most promising in terms of larger impacts such as inventions, new products, or processes [3], [4], [6], [14], [22].

Our data analysis reveals an effect that may help shedding further light on the generation of creative outcomes, namely the relevance of a feature set broadening without a clear task association (\#4), i.e., an individual explores a feature for which no immediate use is evident (to that individual). Our case indicates that such a feature set broadening leaves an individual 
in a state of curiosity and increased cognitive involvement - an important trigger for subsequent creative action [2], [6].
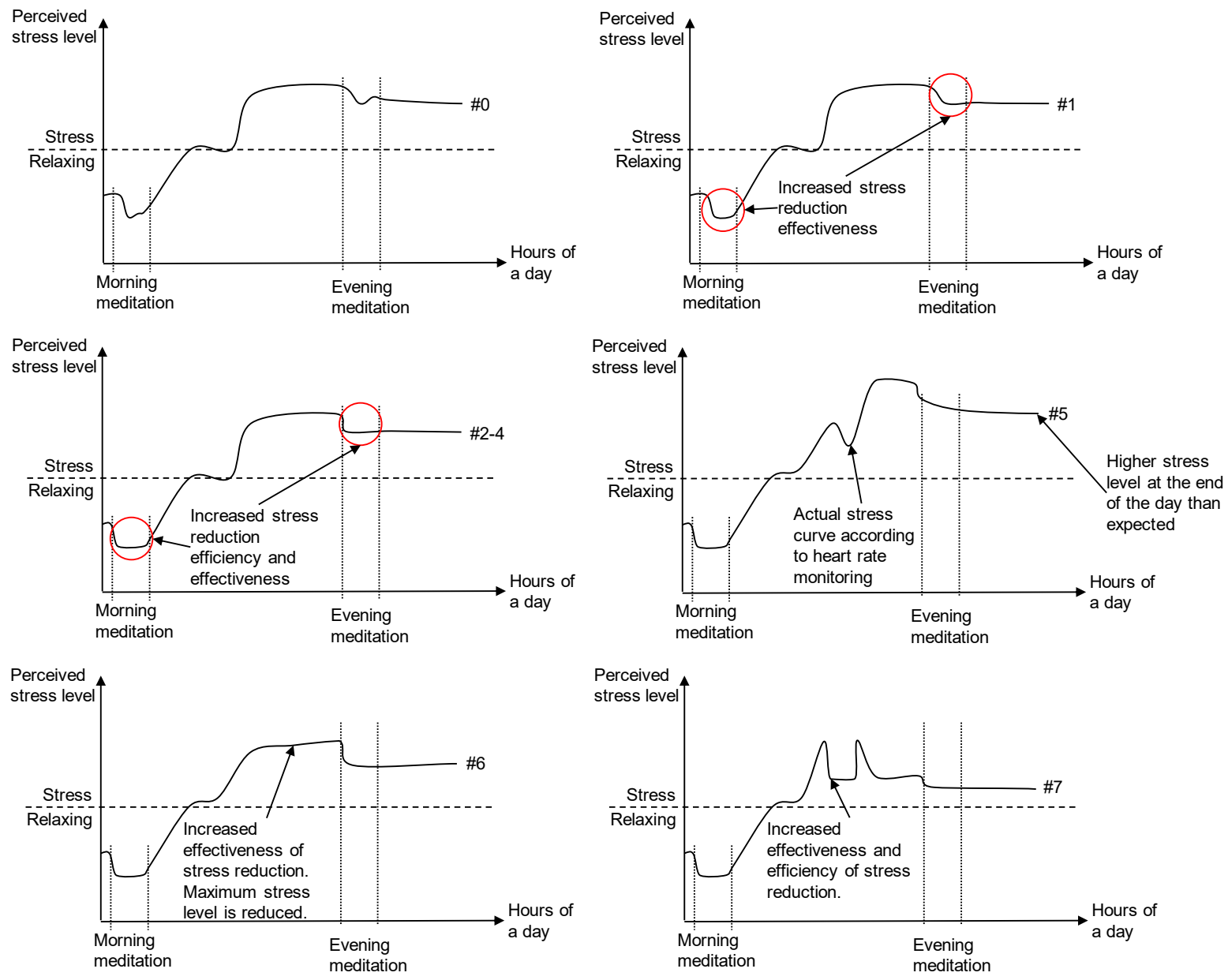

Figure 3. Development of John's stress level during the seven feature set modifications

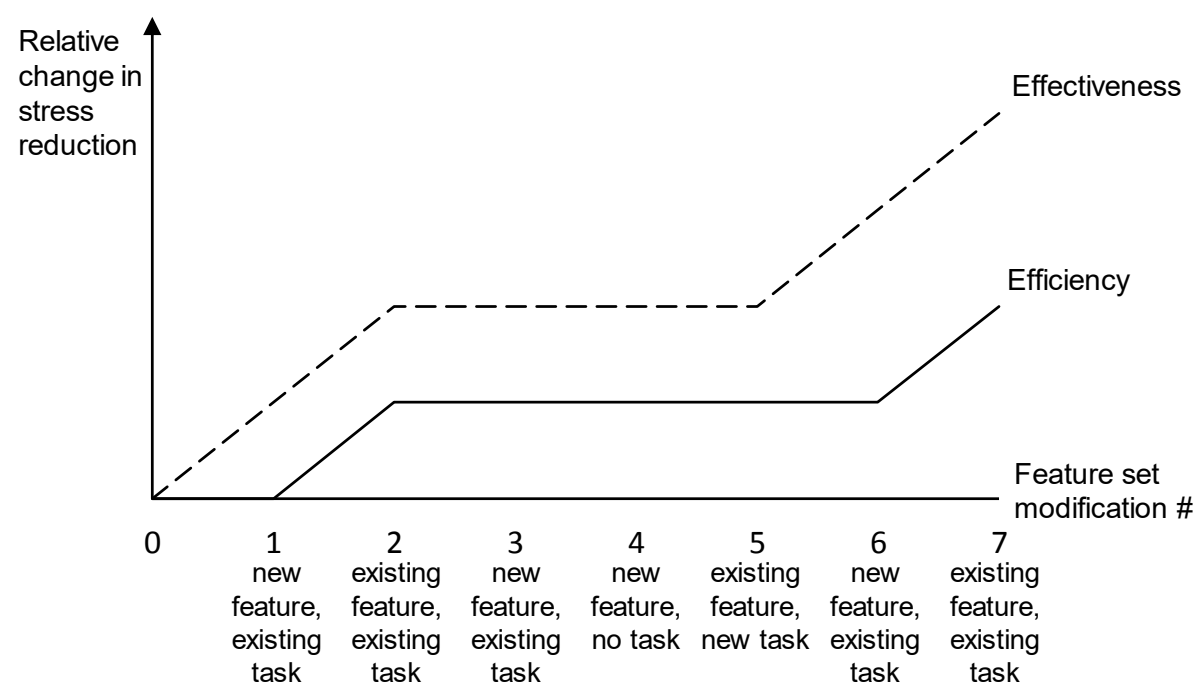

Figure 4. Relative development of change in stress reduction effectiveness and efficiency

To sum up, a strong interrelation between the recombination processes associated to no task and a new task is evident. This situation must not be confused with an unsuccessful recombination process (see $\mathrm{P} 1 \mathrm{c}$ ). While in the case of an unsuccessful recombination, the affected feature set is reset, in the no-task configuration, the discovered feature remains in the features in use, indicating that an individual is convinced that there might be value of a feature, which that person has just not uncovered. Thus: 
P2a: The attainment of creative outcomes of innovative IT use operates via a feature set broadening with no task-related outcomes.

P2b: Only when the feature set broadening does not lead to later reset of the features in use, a subsequent feature set deepening related to new tasks is probable.

From the perspective of performative outcomes of innovative use, we also detected different impacts on task efficiency and effectiveness from the different recombination processes. In the two occurrences of a feature set broadening associated with new features and an existing task $(\# 1, \# 6)$, we detected an impact on effectiveness. While previous literature frequently postulated a more general impact of feature set broadening on performance, [8], [10], [19], a few authors have also speculated on that this type of broadening might be rather related to effectiveness [32]. Furthermore, the impact of this feature set broadening on effectiveness seems lower than that of a feature set deepening (\#2, \#7) related to existing tasks. With respect to task-related efficiency, we were, in our case, only able to detect an impact for feature set deepening related to existing tasks. Evidence for this finding comes from [24], who show that knowledge transformation processes such as feature set deepening will also "streamline" the feature sets and, thus, improve task-related efficiency. We derive:

P3a: Feature set broadening involving new features and only existing tasks has a positive impact on task-related effectiveness.

P3b: Feature set deepening related to existing tasks has a higher positive impact on taskrelated effectiveness than a feature set broadening related to existing tasks.

P3c: Feature set deepening related to existing tasks has a positive impact on task-related efficiency.

\section{Discussion and Conclusions}

Given that one, conveniently sampled case, regardless of its richness and longitudinal character, can only provide limited insights on such a complex phenomenon such as innovating with IT, we see the work presented here as a starting point for future investigations. Case research is, per se, never generalizable. The purpose of case research is to shed light on relevant and complex phenomena that cannot easily be investigated using large samples, but require scrutiny and a high level of granularity to extract the relevant mechanisms. Our case started in a specific private setting. However, the way the person used the IT was completely different (work productivity), and, to some degree, unpredictable. We hold that this situation is prototypical for most innovative use scenarios. Beyond that, we believe that our unique longitudinal research setup, the way we analyze the case, and the way we extract the relevant mechanisms of innovative use allow for the derivation of conclusions that go beyond our case. First, we demonstrate that findings from existing organizational research on IT use also apply to our case. Second, we offer an analytical explanation of the attainment of innovative outcomes. In particular, we show that innovation only occurs through repeating cycles of recombination processes, and propose that it is instrumental to run through a phase that does not benefit any task-related outcomes to trigger true creative outcomes. This insight sheds completely new light on the process of innovating with IT and contributes to the recent and lively discussions in IT use research, on why it is so challenging to thoroughly explain innovative IT use. Our insights are thus relevant both for researchers that investigate innovation with IT, but also for practitioners who want to stimulate more innovative behavior with their employees. In presenting our findings, we hope to stimulate further discussions on the nature of the processes underlying individual innovative IT use. We are confident that our work contributes to both recombination research and research on innovative IT use by shedding light on the nonlinearity of innovating with IT. In particular, we showed that innovating with IT operates in constant cycles of feature set broadening and deepening, with broadening preceding the deepening. By linking feature set broadening and deepening to existing tasks as well as to new deliverables, we clarify the relationships and transitions between different configurations of innovative use and show which patterns of innovative use occur over time. 
Consequently, we can also extend recombination research by showing that the fundamental processes of recombination, broadening and deepening, occur in cycles and show that processes related to individual innovation behavior follow specific patterns. Furthermore, we shed light on the relevance of individuals on innovativeness - a facet, typically not considered in recombination research. On a higher abstraction level, we highlight the role of learning and feature set modifications as the key mechanisms to the attainment of outcomes. Further, we show that users cannot directly move from efficiency or effectiveness-optimizing behavior to innovative behavior, but that at least one exploration cycle that leads to no immediate outcomes needs to be successfully passed. Future researchers may draw on this insight and rather consider how this insight reflects concrete types of post-adoption use and their mutual relationships. Our paper is also of interest to IT practitioners who wish to better understand why the users in their organization arrive at dedicated outcomes. We shed light on the relevance of learning processes and show which behaviors may have to be incentivized to end up with specific task-related results. In addition, the feature set typology and understanding we present provides guidance to set up training programs (e.g. by not only introducing features, but explicitly linking them to multiple tasks and inspiring creative uses) and helps better structuring communication with users in problem situations.

\section{References}

1. L. Argote, E. Miron-Spektor, "Organizational Learning: From Experience to Knowledge.” Org Sci, vol.22, no.5, pp. 1123-1137, 2011, https://doi.org/10.1287/orsc.1100.0621

2. C. M. Flath, S. Friesike, M. Wirth, F. Thiesse, "Copy, transform, combine: Exploring the remix as a form of innovation." JIT, vol.32, no.4, pp. 306-325, 2017, https://doi.org/10.1057/s41265-017-0043-9

3. L. Fleming, S. Mingo, D. Chen, "Collaborative Brokerage, Generative Creativity, and Creative Success." Admin Sci Quart, vol.52, no.3, pp. 443-475, 2007, https://doi.org/10.2189/asqu.52.3.443

4. M. Gruber, D. Harhoff, K. Hoisl, "Knowledge Recombination Across Technological Boundaries: Scientists vs. Engineers.” Mgmt Sci, vol.59, no.4, pp. 837-851, 2013, https://doi.org/10.1287/mnsc.1120.1572

5. A. Majchrzak, L. P. Cooper, O. E. Neece, "Knowledge Reuse for Innovation." Mgmt Sci, vol.50, no.2, pp. 174-188, 2004, https://doi.org/10.1287/mnsc.1030.0116

6. S. Nambisan, R. Agarwal, M. Tanniru, "Organizational mechanisms for enhancing user innovation in information technology." MISQ, vol.23, no.3, pp. 365-395, 1999, https://doi.org/10.2307/249468

7. J. Carlo, K. Lyytinen, G. Rose, "A Knowledge-Based Model of Radical Innovation in Small Software Firms." MISQ, vol.36, no.3, pp. 865-895, 2012.

8. A. Benlian "IT feature use over time and its impact on individual task performance." JAIS, vol.16, no.3, pp. 144-173, 2015, 10.17705/1jais.00391

9. M. K. Ahuja, and J. B. Thatcher, "Moving beyond intentions and toward the theory of trying: Effects of work environment and gender on post-adoption information technology use." MISQ, vol.29, no.3, pp. 427-459, 2005.

10. J. Jasperson, P. E. Carter, R. Zmud, "A Comprehensive Conceptualization of PostAdoptive Behaviors Associated with Information Technology Enabled Work Systems." MISQ, vol.29, no.3, pp. 525-557, 2005, https://doi.org/10.2307/25148694

11. R. Agarwal, "Individual acceptance of information technologies." In Framing the domains of IT management research: Glimpsing the future through the past (Zmud, R. W. Ed.), pp. 85-104, Cincinnati, Ohio: Pinnaflex, 2000.

12. S. Nambisan, "Information Technology and Product/Service Innovation: A Brief Assessment and Some Suggestions for Future Research." JAIS, vol.14, no.4, 2013, https://doi.org/10.17705/1jais.00327 
13. Y. Rahrovani, A. Pinsonneault, "User's Perceived IS Slack Resources and their Effects on Innovating with IT." ICIS 2014, Auckland, New Zealand, 2014, https://doi.org/10.1109/HICSS.2015.500.

14. A. Ortiz de Guinea, J. Webster, "An investigation of information systems use patterns: Technological events as triggers, the effect of time, and consequences for performance." MISQ, vol.37, no.4, pp. 1165-1188, 2013, https://doi.org/10.25300/misq/2013/37.4.08

15. F. F. Bagayogo, L. Lapointe, G. Bassellier, "Enhanced use of IT: A new perspective on post-adoption." JAIS, vol.15, no.7, pp. 361-387, 2014, 10.17705/1jais.00367

16. J. P. A. Hsieh, A. Rai, S. X. Xu, "Extracting business value from IT: A sensemaking perspective of post-adoptive use." Mgmt Sci, vol.57, no.11, pp. 2018-2039, 2011, https://doi.org/10.1287/mnsc. 1110.1398

17. J. P. A. Hsieh, R. Zmud, "Understanding Post-Adoptive Usage Behaviors: A TwoDimensional View." Comp Info Sys Fac Publ, 2006, http://aisel.aisnet.org/digit2006/3

18. H. Sun "Understanding user revisions when using information system features: Adaptive system use and triggers." MISQ, vol.36, no.2, pp. 453-478, 2012, https://doi.org/10.2307/41703463

19. A. Burton-Jones, A., D. W. Straub, "Reconceptualizing system usage: An approach and empirical test." ISR, vol.17, no.3, pp. 228-246, 2006, https://doi.org/10.1287/isre.1120.0444

20. X. Li, J. P. A. Hsieh, A. Rai, "Motivational Differences Across Post-Acceptance Information System Usage Behaviors: An Investigation in the Business Intelligence Systems Context." ISR, vol.24, no.3, pp. 659-682, 2013, https://doi.org/10.1287/isre.1120.0456

21. D. J. Beal, R. R. Cohen, M. J. Burke, C. L. McLendon, "Cohesion and performance in groups: A meta-analytic clarification of construct relations." J Appl Psy, vol.88, no.6, pp. 989-1004, 2003, https://doi.org/10.1037/0021-9010.88.6.989

22. A. Burton-Jones, A., C. Grange, "From Use to Effective Use: A Representation Theory Perspective." ISR, vol.24, no.3, pp. 632-658, 2013, https://doi.org/10.1287/isre.1120.0444

23. K. S. Lassila, J. C. Brancheau, "Adoption and utilization of commercial software packages: Exploring utilization equilibria, transitions, triggers, and tracks." JMIS, vol.16, no.2, pp. 63-90, 1999, https://doi.org/10.1080/07421222.1999.11518246

24. S. Sundaram, A. Schwarz, E. Jones, W. Chin, "Technology use on the front line: How information technology enhances individual performance." J Acad Mark Sci, vol.35, no.1, pp. 101-112, 2007. https://doi.org/10.1007/s11747-006-0010-4

25. L. P. Robert, T. A. Sykes, "Extending the Concept of Control Beliefs: Integrating the Role of Advice Networks." ISR, vol.28, no.1, pp. 84-96, 2017, https://doi.org/10.1287/isre.2016.0666

26. C. K. W. de Dreu, M. A. West, "Minority dissent and team innovation: The importance of participation in decision making." J Appl Psy, vol.86, no.6, pp. 1191-1201, 2001, https://doi.org/10.1037/0021-9010.86.6.1191

27. T. L. Griffith, "Technology Features as Triggers for Sensemaking." Acad Mgmt Rev, vol.24, no.3, pp. p. 472, 1999, https://doi.org/10.5465/amr.1999.2202132

28. G. DeSanctis, M. S. Poole, "Capturing the complexity in advanced technology use: Adaptive structuration theory." Org Sci, vol.5, no.2, pp. 121-147, 1994, https://doi.org/10.1287/orsc.5.2.121

29. A. Ortiz de Guinea, M. L. Markus, "Why break the habit of a lifetime? Rethinking the roles of intention, habit, and emotion in continuing information technology use." MISQ, vol.33, no.3, pp. 433-444, 2009, https://doi.org/10.2307/20650303

30. M. Limayem, M., S. G. Hirt, C. M. K. Cheung, "How habit limits the predictive power of intention." MISQ, vol.31, no.4, pp. 705-737, 2007, https://doi.org/10.2307/25148817

31. H. Barki, G. Paré, C. Sicotte, "Linking IT implementation and acceptance via the construct of psychological ownership of information technology." JIT, vol.23, no.4, pp. 269-280, 2008, https://doi.org/10.1057/jit.2008.12 
32. K. A. Saeed, S. Abdinnour, "Understanding post-adoption IS usage stages: An empirical assessment of self-service IS." ISJ, vol.23, no.3, pp. 219-244, 2013, https://doi.org/10.1111/j.1365-2575.2011.00389.x

33. I. Benbasat, D. K. Goldstein, M. Mead, "The Case Research Strategy in Studies of Information Systems." MISQ, vol.11, no.3, pp. p. 369, 1987, https://doi.org/10.2307/248684

34. L. Dubé, G. Paré, "Rigor in Information Systems Positivist Case Research: Current Practices, Trends, and Recommendations." MISQ, vol.27, no.4, p. 597, 2003.

35. R. K. Yin, Case study research. 4th ed. Thousand Oaks, CA: Sage, 2009.

36. M. B. Miles, A. M. Huberman, j. Saldana, Qualitative Data Analysis. 3rd ed. Thousand Oaks, CA: Sage, 2015.

37. T. W. Ferratt, J. Prasad, E. Dunne, "Fast and Slow Processes Underlying Theories of Information Technology Use." JAIS, vol.19, no.1, 2018.

38. P. G. Audia, J. A. Goncalo, "Past Success and Creativity over Time: A Study of Inventors in the Hard Disk Drive Industry." Mgmt Sci, 53, no.1, pp. 1-15, 2007, https://doi.org/10.1287/mnsc.1060.0593

39. G. Hirst, D. van Knippenberg, J. Zhou, "A Cross-Level Perspective on Employee Creativity: Goal Orientation, Team Learning Behavior, and Individual Creativity." AMJ, vol.52, no.2, pp. 280-293, 2009, https://doi.org/10.5465/AMJ.2009.37308035

40. R. Katila, R., G. Ahuja, "Something old, something new: a longitudinal study of search behavior and new product introduction." AMJ, vol.45, no.6, pp. 1183-1194, 2002., https://doi.org/10.5465/3069433 